\title{
LA CORONA Y LA PROPUESTA DE CANDIDATO A PRESIDENTE DEL GOBIERNO: NUEVAS PRÁCTICAS Y VIEJAS NORMAS
}

\author{
JOSÉ Ma PORRAS RAMÍREZ \\ Catedrático de Derecho Constitucional \\ Universidad de Granada
}

SUMARIO

I. La Corona en la Constitución democrática. II Las funciones con trascendencia jurídica externa del monarca parlamentario. III. La propuesta de candidato a Presidente del Gobierno. IV. Conclusiones.

\section{LA CORONA EN LA CONSTITUCIÓN DEMOCRÁTICA}

Hasta que la Constitución vigente se encargó de demostrar lo contrario, en España se había considerado irrealizable armonizar Monarquía y Democracia; máxime cuando la propia experiencia histórica había demostrado infructuosos los intentos previos de cohonestar, plenamente, siquiera, Monarquía y Parlamentarismo. Así, aún estaba próximo en el tiempo el recuerdo del constante uso hecho de su prerrogativa por parte del titular de la Corona, confiriendo a ésta una posición central en la práctica constitucional. Que la misma se erigiera en suprema instancia de orientación y decisión políticas, al tiempo que en responsable última de las mismas, había convertido a la Monarquía, durante el reinado de Alfonso XIII, en expresión jurídica de la forma de Estado, en protagonista y pieza clave de un sistema que la situaba en su cima y de la que hacía depender su subsisten$\mathrm{cia}^{1}$. De ahí que cuando éste vino a caer, por no permitir ni prever su evolución, la Monarquía se derrumbara con él, una vez frustradas las tentativas posibilistas,

1 Como referencia ya clásica, vid., A. M. CALERo AMOR, «La prerrogativa regia en la Restauración: teoría y práctica (1875-1902)», Revista de Estudios Políticos, nº 55, 1987, pp. 273-315; en especial, p. 275. También, A. LARIo González, El Rey, piloto sin brújula. La Corona y el sistema político de la Restauración (18751902), UNED-Biblioteca Nueva, Madrid, 1999, pássim. 
tímidamente esbozadas y pronto abortadas, que alentaban su efectiva y sincera parlamentarización ${ }^{2}$. Mediante las mismas se pretendía no sólo limitar el poder real, sino lograr el traslado del centro de gravedad político, el eje del poder, desde el monarca hacia el parlamento, a fin de que éste, en su calidad de representante inmediato y auténtico de la soberanía nacional, una vez universalizado el sufragio, monopolizara la relación fiduciaria que legitima la existencia de un gabinete desvinculado, al cabo, tanto orgánica como funcionalmente, de la figura del rey.

Mas en España ese proceso, desarrollado gradualmente en el Reino Unido ${ }^{3}$, en Bélgica ${ }^{4}$ o en los Países Bajos ${ }^{5}$, a través de la mera práctica política, el cual hizo posible el surgimiento de la Monarquía parlamentaria a modo de «construcción consuetudinaria», sin solución de continuidad en el seno de una estructura jurídico-constitucional que no precisaba reconocerla formalmente como tal ${ }^{6}$, fracasó ante la negativa de la Corona, respaldada por los sectores privilegiados a ella, entonces, asociados, a desprenderse de funciones y competencias decisivas. Así, la misma no se avino a quedar relegada al desempeño de cometidos estrictamente simbólico-representativos, declarativos y relacionales, libres, en cualquier caso, del originario poder de gobierno atribuido tradicionalmente al monarca. Esa resistencia impidió, en origen, no sólo superar la vieja tensión dialéctica, durante largo tiempo existente, entre los principios monárquico y de gobierno representativo, sino conjugar a la magistratura regia con las exigencias del principio democrático.

Hubo de ser, por ello, la Constitución de 1978 quien se viera en la necesidad de suplir excepcionalmente una evolución política no experimentada en España, procediendo a refundar jurídicamente, «ex novo», a la institución monárquica.

2 Desde una perspectiva estrictamente doctrinal, vid., A. G. Posada, Las funciones del Rey en el régimen constitucional y parlamentario, La España Moderna, n ${ }^{\circ}$ 167, 1902, pp. 45-62; y A. SALVADOR Y RODRIGÁÑEZ, La prerrogativa regia y la reforma constitucional. RACMP, Madrid, 1924, pássim. Una notable síntesis de estas posiciones, defendidas, también, entre otros, por Azcárate, Ortega, Pedregal, Cossío y Cajal..., vinculadas al ideario regenerador del Partido Reformista, liderado por Melquiades Álvarez, puede consultarse en A. M. Calero Amor, Los precursores de la Monarquía democrática», J. L. García Delgado (ed.), La España de la Restauración. Política, Economía, Legislación y Cultura, Madrid, Siglo xxi, 1985, pp. 21-54; y en M. SuÁrez Cortina, El reformismo en España. Republicanos y reformistas bajo la Monarquía de Alfonso XIII, Madrid, Siglo XXI, 1986, pp. 85-108.

3 V. Bogdanor, The Monarchy and the Constitution, Oxford, Oxford University Press, 1997, pp. 1-41. R. Brazier, Constitutional Practice. The Foundations of British Government, Oxford, Clarendon Press, 2001, pp. 183-205.

4 F. Delpérée, La Constitution: de 1830 à nos jours, et même au-delà, Bruxelles, Racine, 2006, pp. 32 y ss. También, J. STengers, L'Action du Roi en Belgique depuis 1831: pouvoir et influence, Bruxelles, Racine, 1996, pp. 66 y ss. y A. Molitor, La function royale en Belgique, Bruxelles, Centre de Recherche et d'Information Socio-Politique, 1979, pp. 13-71.

5 G. Deneckere, Continuity and discontinuity of the Constitutional Monarchy from a transnational perspective: the Netherlands-Belgium en Low Countries Historical Review, 2015, pp. 1-30. También, C. A. Kortmann, Constitutional Law in the Netherlands, Kluwer Law International, 2007, pp. 64 y ss.; y A. F. MANNING, «De monarchie in Nederland», Res Publica, Vol. XXXIII, 1991/1, pp. 25-40.

6 I. De Otтo y Pardo, Sobre la Monarquía», VVAA, La izquierda y la Constitución, Barcelona, Taula de Canví, 1978, pp. 51-61; en especial, pp. 53-54 y 57-58. 
Así, lejos de concebir, tal que antaño, a la misma como poder constituyente, dotado de soberanía, dispuso su configuración como mero poder constituido, como órgano constitucional, sujeto, de igual forma que los demás, a la Constitución y al resto del ordenamiento jurídico (art. 9.1). Semejante determinación inicial supuso la ruptura con toda relación que, en tal sentido, pudiera dudarse si mantenía, hasta ese momento, con vestigios remanentes del principio monárquico, o con el principio de legitimación personalista que el hecho de haber sido su titular designado por el General Franco podía aún implicar.

Eso explica el deber que obliga a la misma a orientar únicamente su actuación en pos del cumplimiento y la realización de los fines o valores materiales que la Norma Fundamental consagra. Y, asimismo, justifica la propia derivación constitucional del contenido tasado de las atribuciones jurídicas que a la Corona se otorgan, según redundantemente insiste en disponer el art. 56.1 «in fine» $\mathrm{CE}$, a fin de descartar la existencia de derechos originarios, previos e independientes a la Constitución asistiendo al rey ${ }^{7}$.

Es, pues, el principio democrático quien provoca, al proyectarse sobre la regulación normativa de la institución monárquica en la Constitución, una consecuencia que se expresa negativamente. Ésta consiste, en esencia, en la prohibición de que el monarca, en tanto que titular de un órgano no electivo, si bien asociado al desarrollo de la forma parlamentaria de gobierno (art. 1.3 CE), posea poderes jurídicos, considerados propios, de libre y discrecional ejercicio, que le permitan innovar o modificar el ordenamiento de forma independiente. Así, sus actos dotados de trascendencia jurídica externa, expresivos de competencias desprovistas genéricamente de "potestas» o «facultamiento», se considerarán de carácter debido, reglado u obligatorio, al limitarse mediante los mismos a la formalización indisponible de decisiones cuyo contenido no ha determinado, por corresponderle tal función a los órganos representativos que desarrollan, de manera efectiva, la forma de gobierno. Asimismo, tales actos se entenderán de ejercicio dependiente, al precisarse, para estimarlos válidos, que su comisión se efectúe contando con el necesario refrendo de otro órgano estatal habilitado al efecto, que asumirá la responsabilidad que pueda derivarse de los mismos (arts. 56.3 y $64.1 \mathrm{CE})^{8}$.

En suma, de acuerdo con la Constitución vigente, la Corona, cuya posición y competencias se encuentran reguladas, con precisión y detalle suficientes, en el texto constitucional, en contraste con lo observado mayoritariamente en el derecho comparado 9 , ha de contraerse al ejercicio de la función propia y característica

7 J. Ma Porras Ramírez, Principio democrático y función regia en la Constitución normativa, Madrid, Tecnos, 1995 , p. 149. 149-150.

$8 \mathrm{~J} . \mathrm{M}^{\mathrm{a}}$ Porras Ramírez, Principio democrático y función regia en la Constitución normativa, op. cit. pp.

9 Dicho contraste regulador resulta de su comparación con las constituciones europeas que asumen la forma monárquica (con las excepciones danesa y, sobre todo, sueca), las cuales no se han preocupado por 
de la Jefatura del Estado (art. $56 \mathrm{CE}$ ), en el seno de un ordenamiento democrático que asume la variante monárquica de la forma de gobierno parlamentaria (art. $1.3 \mathrm{CE})^{10}$. Tal función tiene como presupuesto la conversión de la magistratura regia en una instancia neutralizada, jurídica y políticamente, que, aun así, está llamada, por expreso mandato constitucional, a trabar una estrecha relación necesaria con los órganos representativos de la voluntad popular que aparecen dotados de competencias de naturaleza y alcance político ${ }^{11}$.

A este respecto, ha de tenerse presente que la Constitución española ha adoptado un modelo de parlamentarismo racionalizado, que no sólo somete a normas jurídicas la relación establecida entre el Legislativo y el Ejecutivo, sino que procura otorgarle la máxima estabilidad a éste, al tiempo que se potencia a la figura de su Presidente, reforzando su posición y competencias. Ello conlleva, al tiempo, la reconducción de la Corona al desempeño estricto de la función propia de la Jefatura del Estado, privándola así de poderes efectivos que incidan en el desarrollo práctico de la forma de gobierno ${ }^{12}$.

\section{LAS FUNCIONES CON TRASCENDENCIA JURÍDICA EXTERNA DEL MONARCA PARLAMENTARIO}

En ese marco interpretativo la Constitución atribuye a la Corona dos cometidos jurídicos fundamentales, ligados a su condición de titular de la Jefatura del Estado. El primero de ellos es aquél por el que se insta a la misma a declarar, tanto en un plano interno como en el ámbito de las relaciones internacionales, la voluntad del Estado-persona. A tal efecto, le compete formalizar jurídicamente, a través de su manifestación solemne y genérica, aquellos actos que, expresando las decisiones de los restantes órganos estatales en el ejercicio de sus competencias, requieren, por expresa previsión constitucional, habida cuenta de su singular trascendencia, la exteriorización certificadora y perfectiva de los mismos, por parte del rey, a fin de hacer así posible, en última instancia, su imputación jurídica

\footnotetext{
ajustar a la realidad la posición y atribuciones de la Corona en sus respectivos Estados. Así, aquéllas sólo se entienden, hoy, si se las interpreta en el marco de un sistema de gobierno gestado habitualmente de forma convencional en el seno de la estructura jurídica efectivamente normativizada de una Monarquía constitucional de configuración dual. Así lo advirtió prontamente L. SÁnChEZ Agesta, «Significado y poderes de la Corona en el Proyecto constitucional», VVAA, Estudios sobre el Proyecto de Constitución, Madrid, CEC, 1978, pp. 93-117; en especial, pp. 112. Más recientemente, G. RolLnERT LIERN (Dir.), Las monarquías europeas en el siglo XXI, Madrid, Sanz y Torres, 2007, pássim.

10 M. Aragón Reyes, «La Monarquía parlamentaria. (Comentario al art. 1.3 de la Constitución)», Dos estudios sobre la Monarquía parlamentaria en la Constitución. Madrid, Civitas, 1990, p. 104.

11 Y. Gómez Sánchez (Coord.), XXV años de Monarquía parlamentaria, Madrid, Sanz y Torres, 2006, pássim.

12 Desde una perspectiva comparada, una completa visión de conjunto de las transformaciones experimentadas en el seno de la forma parlamentaria de gobierno, puede consultarse en S. CECCANTI, La forma di governo parlamentaria in trasformazione, Bologna, Il Mulino, 1997, pp. 98 y ss.
} 
unitaria al Estado. De hecho, la mayor parte de las atribuciones jurídicas asignadas a la Corona en la Constitución y en las leyes aparecen vinculadas a la especial posición de preeminencia formal que viene el titular de la misma a ocupar, ex art. 56.1 $\mathrm{CE}$, en tanto que vértice del aparato organizativo estatal ${ }^{13}$.

Junto a esa función declarativa, la Constitución requiere, asimismo, a la Corona para que ponga formalmente en relación a los órganos representativos que, ejerciendo el poder político, realizan, de modo práctico, el sistema parlamentario de gobierno. Dicha función relacional obliga a la Corona a desarrollar tareas de coordinación y mediación interórganicas, contribuyendo al establecimiento del necesario vínculo que ha de existir entre el Gobierno, el Parlamento y el cuerpo electoral. Tal cometido se traduce en el ejercicio de competencias regladas y, en todo caso, dependientes, que no implican la existencia de una «potestas», o libre capacidad autónoma de actuación y decisión, de carácter discrecional, asistiendo al monarca.

No cabe, por tanto, asociarlas, como en ocasiones se ha hecho indebidamente, a la condición de árbitro y moderador del funcionamiento regular de las instituciones, que el art. 56.1 CE asigna, sin consecuencias jurídicas de ningún tipo, al Jefe del Estado. De lo contrario, se estaría promoviendo la reviviscencia de un «cuarto poder», habilitado, al tiempo, para fungir como garante del orden constitucional establecido ${ }^{14}$. Y no es eso lo que se deduce de la interpretación coherente de un subsistema institucional, oportunamente integrado en el ordenamiento jurídico que la Constitución democrática preside y conforma, el cual no se mueve en las coordenadas histórico-culturales que llevaron a B. Constant a propiciar, en los albores del parlamentarismo continental europeo, la atribución al rey de un «poder neutro» o «preservador», que «recibe y transmite por herencia», a fin de mantenerlo «inaccesible a las pasiones políticas de los ciudadanos».

Un «poder armónico y moderador», «judicial de los otros poderes» (Ejecutivo y Legislativo, fundamentalmente), que lo faculta para «interpretar la opinión», encargando la formación del Gobierno; negando, en su caso, a través del veto, la sanción de las leyes; y disolviendo el Parlamento, cuando estime necesario

13 Como señala H. Kelsen, siempre «la imputación al Estado se efectúa a través de un órgano de éste...», constituyendo su actuación «sólo un punto de transición y no el punto final de la imputación jurídica». El concepto de voluntad del Estado... hay que considerarlo exclusivamente,....como una construcción exigida con vistas a la imputación», pues viene a ser «el punto final de la misma». "Sólo así adquiere sentido decir que la personalidad del Estado es una personalidad jurídica, como lo es la personalidad de los demás sujetos del derecho». Cfr., sus Hauptprobleme der Staatsrechtslebre entwickelt aus der Lehre vom Rechtssatze (1911). (Trad. esp. de la segunda edición alemana, fechada en 1923, Problemas capitales de la Teoría jurídica del Estado, México, Porrúa, 1987, pp. 156-159).

14 En España los numerosos trabajos, siempre sugerentes, de M. Herrero Y Rodríguez De MiÑón son un buen exponente de la pervivencia de estas ideas, rechazadas, hoy, con distinto criterio, por la doctrina mayoritaria. Vid., por todos, su trabajo: «La posición constitucional de la Corona», VVAA, Estudios sobre la Constitución española. Homenaje al Prof. E. García de Enterría, Madrid, Civitas, 1991, Vol. III, pp. 1921 1940. En una misma línea, vid., M. Fernández Fontecha y A. Pérez De Armiñán, La Monarquía y la Constitución, Madrid, Civitas, 1987, pássim. 
o conveniente superar los enfrentamientos y contradicciones que amenazan la estabilidad del sistema político y la preservación de las libertades civiles trabajosamente conquistadas ${ }^{15}$.

A pesar del enorme influjo que esta teoría ejerció durante todo el siglo XIX y que, aun hoy, de forma, a veces latente e inconsciente, sigue advirtiéndose, al aflorar, a modo de vestigio descontextualizado, en la letra de las Constituciones y en los escritos de algunos tratadistas ${ }^{16}$, lo cierto es que la misma, de conformidad con una interpretación sistemática de la Constitución española, ha perdido toda virtualidad y eficacia jurídica, cuando se predica del monarca parlamentario. Y así sucede habida cuenta de su imposible acomodo con una recta comprensión del significado y alcance adquirido por el principio democrático en aquélla. A esos efectos, como ha señalado P. Cruz Villalón, en el paradigma republicano del Estado constitucional contemporáneo ha de certificarse «la mayoría de edad», «la autosuficiencia de la comunidad política». De ahí que en ella no tengan cabida las expresiones de un poder moderador, neutro o arbitral, al ser la propia comunidad política quien «se arbitra y modera a sí misma...y no desde instancias por fuerza exteriores» a ella ${ }^{17}$.

Así, la razón de la insistencia en querer seguir configurando de forma ambivalente al Jefe del Estado, esto es, no sólo como máximo representante de la organización jurídico-política, cuya unidad y continuidad expresa, sino, al tiempo, como titular de una magistratura extraordinaria que goza de un «fondo o reserva de poder», el cual se activa cuando aprecia una situación de crisis que amenaza, a su juicio, el normal funcionamiento de las instituciones estatales e, incluso, si cabe, el propio orden constitucional establecido ${ }^{18}$, probablemente haya que atribuirla a la aún poderosa inercia ideológica del principio monárquico, que genera una desconfianza hacia las respuestas racionales y regladas que, a las situaciones conflictivas o excepcionales, puede ofrecer una Constitución democrática asentada sobre un sistema político devenido inestable y fragmentado ${ }^{19}$.

Además, puede observarse que los ordenamientos que se han preocupado por introducir dichas referencias arbitrales, poniéndolas en relación con el estatus

15 B. Constant, Cours de politique constitutionnel (1820). (Trad. Esp., Madrid, Taurus, 1968, pp. 13 y ss.). También, extensamente, en su obra previa, felizmente recuperada Fragments d'un ouvrage abandonné sur la possibilité d'une constitution républicaine dans un grand pays (1800-1803 y 1810). (Trad. Esp. Madrid, Tecnos, 2013, pp. 189-265).

16 De tales opiniones se hace eco C. EsPosito, «Il Capo dello Stato parlamentare», VVAA, Studi in onore di Emilio Crosa», Milano, Giuffré, 1960, Volume I, pp. 759-784; también, algo después, de forma más completa, en su redacción de la voz «Capo dello Stato en Enciclopedia del Diritto, Milano, Giuffré, 1962, pp. 224-246.

17 P. Cruz Villalón, «De la Monarquía en España», Claves de la Razón Práctica, nº 171, 2007, pp. 4-9; en especial, pp. 5-6.

18 G. U. Rescigno, «Commentario art. 87, I-VII comma» en G.U. Rescigno, A. Cassese y G. DE Vergottini, Commentario della Costituzione a cura di G. Branca (Arts. 83-87): il Presidente della Repubblica, Bologna, Zanichelli, 1978, pp. 134-188; en especial, pp. 134-136.

19 Cfr. una interesante referencia inicial en N. PÉREZ SERrANo, «Función presidencial y poder moderador» (1933), Escritos de Derecho político (I), Madrid, Instituto de Estudios de Administración Local, 1984, pp. $145-166$. 
competencial del Jefe del Estado, lo han hecho, habitualmente, en momentos fundacionales de un nuevo orden constitucional que, por tanto, emerge con la debilidad e inseguridad propias de esas situaciones, precisando, en consecuencia, a juicio de algunos, de un instrumento regulador personalizado ${ }^{20}$.

Con todo, y sean cuales fueren las razones que muevan al constituyente de turno a atribuir al Jefe del Estado tales potestades moderadoras y arbitrales, es claro que las mismas sólo pueden ser asignadas congruentemente a aquél, atendiendo a su condición de órgano electivo, ya venga conferida dicha representatividad democrática al mismo por el cuerpo electoral, de forma directa (caso portugués), ya por el parlamento, indirectamente (caso italiano). Por eso no pueden concederse a un rey, en un ordenamiento constitucional que se diga informado por el principio democrático ${ }^{21}$, a menos que las convenciones y usos políticos hayan ajustado a los tiempos, vaciando de contenido, lo que la letra no modificada de las constituciones, continúa, a veces, desde el siglo XIX, afirmando, tal y como sucede en Bélgica o en los Países Bajos. Mas, en todo caso, a la luz de dicho principio, es insostenible mantener hoy la existencia, incardinado en la concepción clásica del sistema de división horizontal de poderes, de un cuarto residenciado en el Jefe del Estado-monarca parlamentario, que suponga revestir al mismo de facultades arbitrales para actuar como órgano de equilibrio del sistema, tal y como el constitucionalismo europeo decimonónico auspiciaba.

Por tanto, la condición de árbitro y moderador del funcionamiento regular de las instituciones, que se atribuye al rey en la Constitución (art. 56.1 CE), ha de considerarse el mero residuo formal de una función efectivamente desempeñada por el mismo en el pasado, la cual se encuentra, hoy, sin embargo, carente del contenido, de la «potestas» que en su día tuvo asociada, al haberla perdido el monarca, inevitablemente, al producirse un cambio trascendental en el paradigma jurídico-constitucional explicativo de la misma ${ }^{22}$.

20 En general, cfr., W. Kaltefleiter, Die Funktionen des Staatsoberhauptes in der parlamentarischen Demokratie, Köln/Opladen, Westdeutscher Verlag, 1970, pp. 48-67. Con respecto a Francia, G. ConAC, «Titre II: le Président de la République. Article 5», F. Luchaire y G. Conac (dirs.), La Constitution de la République Française. Analyses et commentaires, Paris, Economica, 1987, pp. 229-323; en especial, pp. 238 y ss. Con relación a Italia, G. Silvestri, «Il Presidente della Repubblica: dalla neutralità-garanzia al governo delle crisi», Quaderni Costituzionali, $\mathrm{n}^{\circ} 1,1985$, pp. 47-59.

21 Nada impide, por tanto, que así sea, en cambio, en relación a un Jefe de Estado republicano, dada su legitimidad democrática. Otra cosa será advertir los problemas y disfunciones que este hecho genera en la práctica política. Así, cfr., entre otros, S. GALEOTTI, «Il Presidente della Repubblica: struttura garantistica o struttura gobernante» en Diritto e Società, 1985, pp. 195-221; y G. D’OrAZIO, «Poteri presidenziali ed interpretazioni autoriduttive (e non)», Giurisprudenza Costituzionale, 1987, I, pp. 2396-2419.

22 Así, la función regia de arbitraje y moderación hace, a lo sumo, referencia, hoy, a actuaciones del monarca no constitucionalizadas, dada la dificultad que entraña su reducción a normas jurídicas y la nula voluntad demostrada al respecto por el constituyente, las cuales discurren, normalmente, de forma latente e implícita, informando buena parte del contenido más destacado de su actuación. Se traducen, de forma habitual, en el ejercicio de una, a veces, particularmente intensa influencia política, que permite al rey intervenir, siquiera de manera indirecta o mediata, en la determinación del proceso político. Así, como apreciara W. BAGEHOT, dado que suelen reconocerse a aquél los derechos a animar, advertir y ser consultado, el titular 
Con esas notas características, así redefinidas, la función relacional de la Corona se despliega o materializa en los supuestos que se contemplan en el art. 62 b) de la Constitución española. Conforme a éstos el rey convoca y disuelve las Cortes Generales y convoca elecciones, si bien «en los términos previstos en la Constitución». Y, de la misma forma, disuelve las Cortes y convoca nuevas elecciones en el supuesto excepcional previsto en el art. 99.5 CE, en el que su intervención trae causa de la constatación de la ausencia de voluntad política, por parte del Congreso de los Diputados, de otorgar su confianza y así investir a candidato alguno a la Presidencia del Gobierno. No en vano, esta circunstancia obliga al monarca a certificar dicha falta de acuerdo, que imposibilita el normal funcionamiento del sistema parlamentario de gobierno; $y$, subsiguientemente, a apelar, también de forma reglada, al cuerpo electoral para que renueve el mandato asambleario a fin de así permitir el reinicio de los trámites orientados al establecimiento de la imprescindible relación de confianza que ha de mediar con el Gobierno que se constituya ${ }^{23}$.

Aun así, más allá de tales casos, la Constitución atribuye un protagonismo sustancialmente mayor al rey cuando requiere que ejerza una competencia de naturaleza, también, relacional, por medio de la cual corresponde al mismo «proponer el candidato a Presidente del Gobierno...» (art. 62 d), en relación con el art. 99 CE) ${ }^{24}$. Dicha atribución parece contener, o así se ha venido, por muchos, hasta ahora interpretando, un subsidiario y ancilar «fondo o reserva de poder», de todo punto

de la Corona aparece, de ese modo, facultado para desplegar la singular «anctoritas» que es propia de la magistratura moral que encabeza, la cual es «símbolo de la unidad y la permanencia del Estado». Ello le orienta a desarrollar tareas de impulso, estímulo y mediación política, tendentes a favorecer la buena marcha del Estado, tanto en situaciones normales como de crisis, contribuyendo así a la atenuación o, incluso, la resolución de los conflictos. Mas, lógicamente, las mismas no pueden ir en menoscabo o detrimento de las competencias, dotadas efectivamente de «potestas», atribuidas a los órganos constitucionales que son sus ocasionales interlocutores o destinatarios. Cfr., W. BAgenot, The English Constitution (1867). London, Fontana Press, 1993, pp. 113 y ss. Entre nosotros, vid., entre otros, A. MENÉndez ReXACH, La Jefatura del Estado en el Derecho Público español, Instituto Nacional de Administración Pública, 1979, p. 437. También, G. RollnerT LiERn, El arbitraje y moderación regios en la Constitución española de 1978, Valencia, 2005, pp. 185 y ss.

23 Como se sabe, la disolución voluntaria o facultativa (art. $115 \mathrm{CE}$ ) corresponde decidirla, mediante decreto, al Presidente del Gobierno, siendo al rey a quien formalmente se atribuye la expedición de aquél. Los demás supuestos en los que se contempla la disolución, en este caso, automática de las Cámaras, tienen lugar cuando concurren las circunstancias que prevé expresamente la norma constitucional, esto es, a saber, ya sea por la finalización del mandato de cuatro años para el que fueron elegidos los diputados y senadores: arts. 68.4 y 69.6 CE; ya, de forma anticipada, bien al no lograrse que candidato alguno a la Presidencia del Gobierno obtenga la confianza del Congreso en el plazo de dos meses desde que se realizó la última votación de investidura, ex art. 99.5 CE; bien en el supuesto de que ambas Cámaras hayan aprobado por mayoría de dos tercios la reforma de la Constitución, afectando al Título Preliminar, al Capítulo II, Sección $1^{\text {a }}$ del Título I, o al Título II de la misma, según prevé el art. 168 CE. En todos estos casos, la preceptiva intervención regia no tendrá más cometido que el estrictamente declarativo ya indicado. Vid., ampliamente, A. BAR CENDÓN, La disolución de las Cámaras Legislativas en el ordenamiento constitucional español, Madrid, Monografías del Congreso de los Diputados, 1989, pp. 169 y ss.

24 Orienta estrictamente al ejercicio de semejante función relacional la competencia otorgada al monarca parlamentario I. DE OTTO Y PARDO, «La posición constitucional del Gobierno», Documentación Administrativa, $\mathrm{n}^{\circ} 188,1980$, pp. 139-182; en especial, pp. 157-162. 
excepcional en atención a lo hasta ahora expuesto, que faculta al mismo para actuar, en determinadas situaciones, con un cierto margen de discrecionalidad.

Se impone, por tanto, establecer una interpretación constitucionalmente adecuada de unos preceptos a los que se ha venido asignando una relevancia desmedida, que no se compadece con el marco interpretativo en el cual han de explicarse las competencias dotadas de trascendencia jurídica externa atribuidas a la Corona en la Constitución. Para ello contamos con el auxilio que proporciona la experiencia acumulada en la aplicación de tales normas, la cual se ha visto notablemente enriquecida durante el año crítico de 2016, esto es, durante la efímera $\mathrm{XI}^{\mathrm{a}}$ Legislatura y el inicio de la XII ${ }^{\mathrm{a}}$, período durante el cual se han generado usos y convenciones, fruto de la práctica política, hoy incorporadas a la determinación del significado y alcance de unas normas constitucionales que han quedado así despojadas de potenciales exorbitancias, disconformes con los objetivos y fines que establece la propia Norma Fundamental.

\section{LA PROPUESTA DE CANDIDATO A PRESIDENTE DEL GOBIERNO}

La competencia en cuestión se orienta estrictamente a la realización por parte de la Corona de un cometido impulsor tendente a activar el proceso de formación del Gobierno, el cual lo es, propiamente, de investidura de su Presidente. El objetivo último que mediante la misma se persigue no es otro que hacer posible el funcionamiento pleno y efectivo del sistema parlamentario ${ }^{25}$. Por tanto, la suya es una actuación previa a la creación de la relación fiduciaria que ha de establecerse entre los órganos políticos a quienes corresponde su ejercicio. A tal fin, la Constitución ha determinado que sea el rey, en tanto que Jefe del Estado, tal y como sucede en otros ordenamientos afines al nuestro, como el alemán ${ }^{26}$, quien promueva la iniciativa de presentación al Congreso de los Diputados del candidato a ocupar la Presidencia del Gobierno.

De acuerdo con el art. 99.1 de la Constitución, dicho procedimiento se iniciará «después de cada renovación del Congreso de los Diputados, y en los demás supuestos constitucionales en que así proceda». Por tanto, dos acontecimientos, cualitativamente diferentes, motivan su apertura: la celebración de elecciones y el cese del Gobierno, siempre y cuando, en este último caso, el mismo no se produzca por la pérdida de la confianza parlamentaria derivada de una moción de censura, ya que ésta comporta, dado su carácter constructivo, la automática investidura de un candidato alternativo propio (art. $113 \mathrm{CE}$ ).

25 I. DE OTTO Y PARdo, «La posición constitucional del Gobierno», op. cit., p. 157.

26 J. C. Colliard, «La designation du Premier Ministre en régime parlementaire», VVAA, Mélanges offerts à Georges Burdeau, Paris, LGDJ, 1977, Vol. II, «Le Pouvoir», pp. 87-114; en especial, pp. 107 y ss. 
En todo caso, debe constatarse que, hasta el presente, salvo en 1981, cuando se produjo la dimisión del Presidente Suárez, el procedimiento del art. 99 CE se ha desarrollado siempre tras la celebración de procesos electorales a Cortes, no revistiendo una especial complejidad. Sin embargo, la mayor fragmentación adquirida por el sistema de partidos, desde las elecciones de 20 de diciembre de 2015, ha dificultado considerablemente su desarrollo, generando prácticas inéditas en la democracia parlamentaria española, las cuales vienen a complementar las previsiones del precepto constitucional de referencia.

Así, como es lógico que suceda en el contexto de una Monarquía parlamentaria, informada por el principio democrático, la propuesta regia de un candidato a Presidente del Gobierno no es libre, sino que se encuentra condicionada, al concretarse tras evacuar las consultas preceptivas (art. 99.1 CE), que permiten al rey conocer fehacientemente la voluntad de la Cámara. Tales consultas adquieren así una importancia determinante, pues se supedita a ellas la selección del candidato propuesto. El titular de la Corona las evacuará, a fin de obtener toda la información necesaria, en primer lugar, con el Presidente del Congreso de los Diputados, el cual, además de trasladarle su propia opinión al respecto, le facilitará, a petición de las propias fuerzas políticas representadas en la Cámara, la relación de interlocutores con los que se reunirá27 ${ }^{27}$ Seguidamente, el rey, a través de los servicios de su Casa, enviará al Congreso de los Diputados la convocatoria de los encuentros que mantendrá con aquéllos, a fin de que la Cámara notifique las fechas y las horas de reunión a los representantes de los grupos políticos. Dicha convocatoria, que habrá de contar, como es preceptivo, con el refrendo del Presidente del Congreso, podrá establecerse sin tener por qué aguardar a que expire el plazo de cinco días, determinado en el art. 24.1 RCD, para la constitución de los grupos parlamentarios.

Además, según se ha hecho costumbre, dicha convocatoria seguirá el orden inverso al que predeterminan los resultados electorales, esto es, de menor a mayor representación parlamentaria. En todo caso, conforme a la Constitución, se requiere que los así llamados sean individuos «designados por los grupos políticos con representación parlamentaria», por lo que no se exige que tengan la condición de diputados, resultando, a esos efectos, indiferente que los grupos políticos a los que representan se integren en grupos parlamentarios propios, o en el mixto. Asimismo, la práctica política ha hecho posible, en el caso de las coaliciones electorales, que el rey convoque a tales consultas, atendiendo a la voluntad expresada por los grupos y agrupaciones de electores que las integran, bien a un solo representante de aquéllas, bien a los portavoces de los diferentes colectivos

27 Como señala J. VINTRó, el Presidente del Congreso no debe excluir de esa relación formalizada por escrito a ningún solicitante cuyo derecho se vea amparado por el art. 23.2 CE, interpretado en relación con el art. 99.1 CE. De lo contrario, cabe la interposición de recurso de amparo contra la misma. Cfr. J. ViNTRó i CASTElls, La investidura parlamentaria del Gobierno: perspectiva comparada y Constitución española, Madrid, Congreso de los Diputados, 2006, pp. 284-285. 
que forman parte de las mismas, sin atender, por tanto, al hecho de que, en la Cámara, sean todos miembros de un mismo grupo parlamentario.

Y aunque nada impide que, eventualmente, se reúna, asimismo, con actores políticos o personajes públicos notorios, cuya opinión tenga a bien recabar de forma previsiblemente confidencial, sólo a las consultas con los individuos designados por los grupos políticos con representación parlamentaria cabe considerarlas preceptivas, al ser éstas las únicas que aparecen dotadas de relevancia constitucional, ex art. 99.1 CE. Dichas consultas suministrarán al monarca una información precisa acerca de las posiciones defendidas por las distintas fuerzas políticas representadas en la Cámara y, lo que es más importante, al ser éste el objetivo que con las mismas se persigue, aquéllas le permitirán conocer su intención, o no, de respaldar a un candidato a ser investido Presidente del Gobierno ${ }^{28}$.

Así, las consultas se iniciarán, con ocasión de la renovación de las Cortes, tras la constitución del Congreso y la elección de su Presidente; e, inmediatamente, en los supuestos de cese del Gobierno por cualquiera de los motivos contemplados por la Constitución (art. 101.1 CE). En cualquier caso, las consultas no tienen fijado plazo alguno de realización, que podrá extenderse en función de las circunstancias políticas concurrentes, a fin de que la propuesta regia acoja el resultado de las negociaciones políticas en curso, caso de no haber culminado éstas. En la práctica, cada ronda de las mismas se ha venido desarrollando durante un período que oscila entre los dos y los cuatro días; pudiendo reiterarse cuantas veces el rey, con el beneplácito del Presidente del Congreso, considere necesario $^{29}$.

Dado que las consultas poseen la condición de actos preparatorios de la decisión final a adoptar, es claro que las mismas vinculan al monarca. La experiencia hasta ahora acumulada, resultante del propio funcionamiento del sistema de partidos, así se ha encargado de demostrarlo sin excepciones. No se comprende por ello la insistencia en apelar a la supuesta libertad o independencia de que goza el rey en orden a determinar su propuesta, ateniéndose a un supuesto criterio político autónomo. Y es que no existe fundamento constitucional alguno que habilite al monarca para efectuar aquélla, realizando un juicio político de oportunidad o conveniencia acerca de la persona a la que considera el candidato más idóneo.

A ese respecto, conviene reiterar, una vez más, su expreso sometimiento al principio democrático, el cual, al proyectarse sobre la forma parlamentaria de gobierno, en general, y sobre la propia posición constitucional de la Corona, en particular, certifica la ausencia de «potestas» regia, esto es, de libre capacidad

28 O. Alzaga Villaamil, Comentario sistemático a la Constitución española de 1978, Madrid, Marcial Pons, 2016, p. 317.

29 Así lo constata, señalando como única excepción la que se produjo en 1982, J. ViNTRó i CASTELLS, «Artículo 99: el procedimiento para el nombramiento del Presidente del Gobierno», M. E. CASAs BAAmonde y M. Rodríguez-Piñero y Bravo Ferrer (Dirs.), Comentarios a la Constitución española. XXX aniversario, Madrid. Wolters Kluwer, 2007, pp. 1654-1663; en especial, p. 1656. 
autónoma de actuación y decisión, para incidir en el desarrollo de un proceso que tiene al rey por notario y testigo cualificado, pero que ha de discurrir autónomamente, conforme a la lógica propia del sistema de partidos ${ }^{30}$.

Se constata así como la Norma Fundamental española no ha hecho sino emular, también en este aspecto, lo dispuesto en la Constitución alemana, precursora de la incorporación de un modelo parlamentario plenamente racionalizado, orientado a procurar tanto la estabilidad, como a reforzar las atribuciones de un Ejecutivo monista, al tiempo que a reducir al máximo las prerrogativas discrecionales del Jefe del Estado ${ }^{31}$. Por eso vino a determinarse, de un modo análogo, que al rey únicamente le compete la iniciativa de presentación al Congreso de los Diputados del candidato a ocupar la Presidencia del Gobierno. Propuesta ésta, que no designación previa, de la cual se da traslado a la Cámara para que sea ella quien, en su caso, otorgue su confianza al mismo, invistiéndolo, si alcanza la escasamente exigente mayoría requerida, esto es, la mayoría simple, favorable, de los votos de los asistentes, en segunda votación, ex art. 99.1 a 3, tras juzgar el programa del Gobierno que aquél pretende formar.

Se comprueba así lo mediatizada que se encuentra, a la hora de su ejercicio, la competencia regia. No en vano, en España, a diferencia de lo que sucede en Bélgica o en los Países Bajos (por no referirse a lo que acontece en repúblicas como la italiana), el Jefe del Estado no se involucra, ni compromete en la negociación política, acudiendo, siquiera, a tales efectos, la figura de un «informador». Tampoco contribuye a aproximar a las partes, fraguando los apoyos a un Gobierno en cuya composición y programa político influye, por medio de la elección de un «formador», que sólo tras alcanzar un acuerdo comparece ante la Cámara para obtener la confianza parlamentaria que ratifica su nombramiento ${ }^{32}$.

Muy al contrario, en España se sigue un procedimiento distinto, y sin duda más evolucionado, en el que no se concibe que el monarca realice una labor de ayuda y suplencia, de mediación y arbitraje, tal que sucedió en tiempos pretéritos.

30 Como señalara M. García Pelayo, como característica propia del moderno Estado de partidos: «en el régimen parlamentario, el sistema de partidos en un período legislativo dado (es quien) predetermina o condiciona qué partido o coalición de partidos ocuparán el Gobierno», pues «el sistema de partidos (la posición de cada uno en el Parlamento y las relaciones entre ellos) condiciona la estabilidad gubernamental y puede abocar a la debilidad y rápida rotación gubernamental de las coaliciones lábiles, lo que puede llegar a acumular disfuncionalidades o incluso llegar a provocar la destrucción de los regímenes democráticos como se demostró en el período de entreguerras». Cfr., su obra El Estado de partidos, Madrid, Alianza, 1986, p. 102.

31 Cfr., al respecto, como referencias clásicas acerca del modelo parlamentario alemán, E. FRIESENHAHN, «Parlament und Regierung im modernen Staat, Veröffentlichungen der Vereinigung der Deutschen Staatsrechtslehrer, 16, 1958, pp. 9-65; y U. SCHEUNER, «Entwicklungslinien des parlamentarischen Regierungssystems in Gegenwart», Festschrift für Adolf Arndt, Frankfurt am Main, Europäische Verlagsanst, 1969, pp. 385-404.

32 El modelo belga se encuentra analizado exhaustivamente, de forma ya clásica, por A. MOLITOR, La fonction royale en Belgique, op. cit., pp. 26 y ss. Acerca del muy intervencionista modelo italiano, vid., entre otros, G.U. Rescigno (a cura di), Evoluzione del sistema político-istituzionali e ruolo del Presidente della Repubblica, Torino, Giappichelli, 2011, pássim. También, N. Maccabiani, M. Frau, E. Tira, «Dalla crisi del IV Governo Berlusconi alla formazioni del I Governo Monti», Associazione Italiana dei Costituzionalisti 1/2012. 
Por eso, conforme a la Constitución y a los usos políticos generados en orden a su aplicación, el rey ha de contraer su intervención a la selección del candidato a la presidencia del Gobierno, la cual, en puridad, resultará del acuerdo al que hayan llegado por su cuenta los grupos políticos representados en el Congreso ${ }^{33}$.

A ese fin, para instrumentar jurídicamente su propuesta, el monarca ha de cerciorarse de que el candidato seleccionado acepte su ofrecimiento, requisito que no debe despreciarse, pues cabe contemplar la posibilidad fáctica de que el mismo decline aquél, tal y como hiciera M. Rajoy en 2016. Pero, en todo caso, el rey no tiene por qué atenerse a la previsión, no exigida por la Constitución, de que el candidato deba ser un parlamentario ${ }^{34}$ (aunque, hasta ahora, así lo haya sido siempre y, sin duda, convenga que lo sea); ni que tenga que ser, necesariamente, el representante designado al efecto por el partido o coalición de partidos más votado en las últimas elecciones celebradas. Únicamente se entiende que deberá orientar su propuesta a la garantía de su viabilidad parlamentaria y al teórico aseguramiento, dentro de lo siempre incierto del vaticinio, de la formación de un Gobierno estable, suficientemente respaldado en la Cámara, pues a ese fin se orientan las consultas que mantiene con los representantes políticos ${ }^{35}$.

A esos efectos, la regulación normativa que se expresa en la propia Constitución y en el Reglamento del Congreso de los Diputados, si bien confieren al rey el monopolio de la iniciativa de presentación del candidato, al no contemplarse, como en Alemania, la contrapropuesta parlamentaria $\left(\text { art. } 63.3^{\circ} \mathrm{LFB}\right)^{36}$, intentan propiciar la búsqueda de acuerdos políticos que allanen la investidura, en el supuesto de que ningún candidato cuente con el respaldo previo de la mayoría de apoyos inicialmente requerida. De ello da fe la relativa amplitud de los plazos que han de mediar entre la celebración de las elecciones y la constitución de la Cámara: veinticinco días, ex art. 68.6 CE; momento tras el cual se celebrarán las consultas; y entre dicha constitución y la apertura de la legislatura: quince días, según dispone el art. 5 RCD, acto éste que debe entenderse como pórtico de la primera votación de investidura del candidato propuesto formalmente por el monarca (art. $170 \mathrm{RCD}$ ).

33 A. Bar Cendón, «Artículo 99: nombramiento del Presidente del Gobierno», O. Alzaga VillaAMIL (dir.), Comentarios a la Constitución española de 1978. Tomo VIII: artículos 97 a 112, Madrid, Cortes Generales/Edersa, 1998, pp. 245-306; en especial, pp. 274-275.

34 El art. 11 de la Ley 50/1997, de 27 de noviembre, del Gobierno, determina que: «Para ser miembro del Gobierno se requiere ser español, mayor de edad, disfrutar de los derechos de sufragio activo y pasivo, así como no estar inhabilitado para ejercer empleo o cargo público por sentencia judicial firme y reunir el resto de requisitos de idoneidad previstos en la Ley 3/2015, de 30 de marzo, reguladora del ejercicio del alto cargo de la Administración General del Estado».

35 Aguiar De Luque, L. «La estructura del proceso de formación del Gobierno. El caso español en el marco del Derecho comparado», Revista de Derecho Político, no 6, 1980, pp. 61-81; en especial, pp. 72 y ss.

36 En dicho precepto se dispone que «Si la persona propuesta por el Presidente Federal no resultare elegida por el Bundestag, éste podrá elegir, por más de la mitad de sus miembros, un Canciller Federal dentro de los catorce días siguientes a la votación». Acerca de esta contrapuesta, cfr., G. Hermes, «Artikel 63: Wahl und Ernennung des Bundeskanzlers», H. Dreier (herausgegeben), Grundgesetz Kommentar, Band II. Artikel 20-82», Tübingen, Mohr Siebeck, 2015, pp. 1185-1207; en especial, pp. 1200-1202. 
Además, no hay que olvidar que no existe plazo para la celebración de dicho pleno de investidura, que la Presidencia del Congreso está, en todo caso, obligada a convocar, una vez que recibe la comunicación de la Casa Real que contiene la propuesta regia de un candidato ${ }^{37}$. Esa ausencia de plazo permitió, en 1996, al Presidente del Congreso retrasarlo tres semanas (y no una, como venía siendo lo acostumbrado), a fin de que el candidato propuesto por el rey, J. $\mathrm{M}^{\mathrm{a}}$ Aznar, contara con un período de tiempo suplementario para culminar las negociaciones políticas destinadas a la obtención de la imprescindible confianza parlamentaria ${ }^{38}$. Asimismo, en febrero de 2016, el Presidente del Congreso hizo lo propio, anunciando su intención de posponer dicho pleno cuatro semanas, a fin de facilitar la obtención de un acuerdo por parte del candidato propuesto, P. Sánchez; pleno éste que se celebró en la fecha predeterminada, a pesar de no haber alcanzado dicho candidato los apoyos necesarios para su investidura. Y, nuevamente, se recurrió a este flexible margen añadido, al inicio de la XII ${ }^{a}$ Legislatura, a fin, en este caso, de favorecer las posibilidades de investidura del candidato M. Rajoy. Mas en esta ocasión se desbordaron todas las previsiones, ya que la prolongación infructuosa de las negociaciones desde que el rey efectuara su propuesta, se vio acompañada de la negativa de la Presidenta del Congreso a fijar un plazo para la convocatoria del pleno de investidura. Sólo cuando, casi tres meses después, el candidato obtuvo garantías de obtener la confianza de la Cámara pudo darse continuidad al procedimiento, interrumpido, hasta ese momento, en su secuencia temporal lógica. Fue entonces cuando el monarca, convocando una nueva ronda de consultas, constató dicho acuerdo y la consiguiente viabilidad parlamentaria de su propuesta, la cual abrió paso, de forma casi inmediata, a la sesión de investidura ${ }^{39}$.

El transcurso de tan prolongado e indeterminado espacio de tiempo desde la obtención de los resultados electorales, (período que, obviamente, resulta sustancialmente más breve, pese a la mencionada flexibilidad con la que cuenta, a la hora de proceder a su determinación, la Presidencia del Congreso, en los casos en que la propuesta regia del candidato sucede a la dimisión, procesamiento, incapacitación o muerte del Presidente del Gobierno, y no a una renovación de las Cámaras), facilita que, en condiciones normales, sea el propio sistema de partidos quien autorregule el acuerdo, determinando, por sí mismo, el nombre de la persona que, al concitar los apoyos mayoritarios de los grupos políticos con representación parlamentaria, posee la expectativa fundada de alcanzar la investidura en el Congreso.

37 La convocatoria de dicho pleno comporta, de forma indisponible para el mismo, el obligatorio sometimiento a dicha sesión de investidura del candidato propuesto por el monarca. Así, ha de recordarse el tenor literal de lo dispuesto en el art. 99.2: «El candidato propuesto...expondrá ante el Congreso de los Diputados el programa político del Gobierno que pretenda formar y solicitará la confianza de la Cámara». 184 y ss.

38 J. Ma. Reniu i Vilamala, La formación de los gobiernos minoritarios en España, Madrid, CIS, 2002, pp.

39 La primera propuesta regia del candidato M. Rajoy se comunicó a la Presidenta del Congreso el 28 de julio de 2016. La nueva propuesta regia del mismo candidato se produjo el 25 de octubre de 2016, no celebrándose el pleno de investidura hasta el 29 de octubre de ese año. 
Eso hace que la ronda de consultas del monarca pueda convertirse en un mero trámite protocolario, en el que los representantes designados por los grupos políticos se limitan a comunicar al rey la decisión adoptada, para que éste actúe como simple vehículo transmisor de la misma ${ }^{40}$. Así sucederá, tanto en las ocasiones en las que el candidato de una fuerza política goza del respaldo de una mayoría absoluta en el Congreso, como en aquéllas en las que los grupos políticos comuniquen al rey, en el curso de las consultas celebradas con el mismo, su intención de ofrecer su apoyo mayoritario a un candidato determinado.

Bien distinto es, no obstante, el escenario cuando se observa la existencia de una particular fragmentación del espectro político-parlamentario y no se vislumbra un acuerdo mayoritario en la Cámara en torno a la figura de un candidato concreto. Una tal situación de Hung Parliament ${ }^{41}$, reveladora de la incapacidad del sistema de partidos por autorregularse, se observó, por primera vez, en España, a principios de 2016, suscitando la duda acerca de si aquélla permitía, o no, la activación de un supuesto "poder de reserva», en realidad, de ayuda y mediación subsidiaria, por parte del rey, orientado a promover, de forma extraordinaria, la integración de las voluntades y la materialización de un acuerdo político. ¿Había de actuar el rey, en casos como el indicado, como catalizador, favoreciendo, mediante sus requerimientos arbitrales, la adopción de soluciones que hicieran posible, en torno a la persona de un candidato, el entendimiento entre las diversas formaciones políticas minoritarias? O dicho de otro modo, ¿debía considerarse cometido del rey desbloquear situaciones persistentes de parálisis o impasse político, a fin de hacer posible, a toda costa, la constitución del Gobierno ${ }^{42}$

Esta duda razonable, avalada por la regulación abierta y sumaria que se contiene en el art. 99 de la Constitución, quedó disipada en atención a la práctica política que vino a desarrollarse. Por medio de la misma se generaron unos usos o convenciones que reglaron el ejercicio de la competencia regia en situaciones como la descrita, vaciándola de todo componente extraordinario y discrecional. Tales usos constitucionales, creados en 2016, fueron, además, determinados, en buena medida, por iniciativa de la propia Corona, cuyo titular, una vez evacuadas las consultas preceptivas, pese a no apreciar la existencia de un acuerdo inicial entre los grupos políticos representados, decidió dar curso al procedimiento, a fin de que el plazo previsto de dos meses, a partir de la primera votación de investidura, comenzara a transcurrir, no generándose una situación indefinida de bloqueo institucional.

40 J. L. Requejo Pagés, «Las relaciones entre el Gobierno y las Cortes Generales», Revista Española de Derecho Constitucional, n ${ }^{\circ}$ 70. 2004, pp. 73-89; en especial, p. 80.

41 V. Bogdanor, The Monarchy and the Constitution, op. cit., pp. 145 y ss.

42 I. DE OTto Y PARdo, «La posición constitucional del Gobierno», op. cit., pp. 155 y ss. También, M. Revenga SÁNCHEZ, «La formación del Gobierno en la Constitución de 1978», Madrid, CEC, 1988, pp. 138 y ss. Y J. M M Porras RAmíreZ, «Monarquía parlamentaria, función regia y poder de reserva de la Corona en la Constitución», VVAA, Estudios de Derecho Público en homenaje a Juan José Ruiz-Rico, Madrid, Tecnos, Volumen I, pp. 194-208. 
Así, inicialmente, el monarca ofreció al candidato del partido con mayor representación parlamentaria someterse a la votación de investidura en el Congreso ${ }^{43}$, pero éste comunicó al rey su renuncia, al no contar con los apoyos necesarios para alcanzar la confianza de la Cámara. Tras ello, el monarca realizó el ofrecimiento al candidato del partido siguiente en número de escaños, el cual aceptó la propuesta tras afirmar su confianza en la posibilidad de obtener la investidura parlamentaria, siquiera en segunda votación (art. 99.3 CE). Mas lo cierto es que no obtuvo la misma, una vez expuesto su programa de Gobierno (art. 99.2 CE), ya que no consiguió culminar las negociaciones políticas que, con ese fin, había iniciado a esos efectos. Tal hecho condujo al rey a reiniciar el procedimiento, tal y como prevé la Constitución en su art. 99.4, convocando, a esos efectos, una nueva ronda de consultas. La misma le permitió llegar al conocimiento fehaciente de que ningún candidato contaba con apoyos suficientes para obtener la investidura parlamentaria, no dándose, por tanto, las condiciones exigidas para someter una nueva propuesta a la Cámara. Transcurrido el plazo de dos meses, a partir de la primera votación de investidura y una vez constatado que ningún candidato había obtenido la confianza del Congreso, el rey invocó el art. 99.5 de la Constitución, procediendo así a decretar, con el refrendo del Presidente del Congreso, la disolución automática de las Cortes y la convocatoria de nuevas elecciones ${ }^{44}$.

Con ese proceder el rey evitó el abandono de la posición «supra partes» que la Constitución le había conferido. Fue consciente así de que su implicación en la lucha política le habría reportado críticas por el abandono de aquélla. De ahí que, prudentemente, desoyera los cantos de sirena que le instaban, tan interesada como erróneamente, bien a no efectuar propuesta alguna, bien a promover una candidatura alternativa a las sugeridas por los principales partidos políticos, una vez fracasadas las alentadas por éstos. De ese modo, hizo patente que la responsabilidad política que la Constitución atribuye implícitamente al sistema de partidos en el procedimiento para el nombramiento del Presidente del Gobierno no tiene que trasladarse, en ningún caso, a una magistratura que simboliza la unidad y permanencia del Estado, y que, por tanto, ha de quedar al margen de los enfrentamientos y luchas partidistas, limitándose, a lo sumo, a constatar el acuerdo o el desacuerdo alcanzado por aquéllos.

43 Se manifiesta a favor de que el rey siga, en su propuesta, el orden que se deduce de los resultados electorales, a fin de evitar que su prestigio pueda verse comprometido, siendo acusado de parcialidad, F. Astarloa Villena, «Artículo 62 (apartados a-e): atribuciones del rey», O. Alzaga Vilaamil (dir.), Comentarios a la Constitución española de 1978», Tomo V: artículos 56 a 65, Madrid, Cortes Generales/Edersa, 1997, pp. 217-229; en especial, p. 227. También, en un mismo sentido, E. BElda PÉREz-Pedrero, El poder del rey. Alcance constitucional efectivo de las atribuciones de la Corona. Madrid, Senado, 2003, pp. 351 y ss.

44 Cfr., una valoración negativa acerca de la actuación protagonizada por los grupos políticos en las tres rondas de consultas celebradas tras las elecciones generales de 20 de diciembre de 2015 en Y. GÓMEZ SÁNCHEZ, «La Monarquía parlamentaria en la Constitución de 1978: valoración y propuestas de reforma constitucional», T. Freixes SAnjuan y J. C. Gavara de CARA (coords.), Repensar la Constitución. Ideas para una reforma de la Constitución de 1978: reforma y comunicación dialógica. Parte primera, Madrid, CEPC, 2016, pp. 92-97. 
Un distinto proceder nos hubiera retrotraído, en España, a las coordenadas ideológicas, felizmente superadas, de la Monarquía de Alfonso XIII, en las que el rey, una vez roto el sistema del turno, con las convenciones a él asociadas, y divididos en facciones los partidos que, antaño, lo protagonizaban, se vio obligado a adoptar decisiones arbitrales mediante las que encargaba la formación del Gobierno al representante de un bando político, el cual adquiría así un liderazgo no obtenido por otras vías. De ese modo, el monarca vino a involucrarse en la dialéctica política, lo que acabó generando, a la postre, un deterioro irreversible del prestigio e imagen públicas de la propia institución regia ${ }^{45}$. Un comportamiento el suyo que, por cierto, no tuvo inconveniente en imitar, con análogas consecuencias, evidenciando así, a la postre, los errores de configuración del sistema, $\mathrm{N}$. Alcalá-Zamora, durante su mandato como presidente de la II República ${ }^{46}$.

Muy al contrario, sabedor de encontrarse en un marco constitucional de actuación bien distinto, Felipe VI no pretendió suplir, ni condicionar el ejercicio de la función que los partidos políticos tienen encomendada en el proceso de investidura del Presidente del Gobierno. Puso así de manifiesto que, conforme al modelo parlamentario adoptado por la Constitución española, no es la Corona quien designa o nombra al Jefe del Ejecutivo, sino el Congreso de los Diputados, el cual ha de ser quien ratifique la decisión que, a través del Jefe del Estado, le ofrecen los grupos políticos con representación parlamentaria. No en vano, esa irrestricta libertad resolutoria de la Cámara Baja permite conciliar la actuación del monarca con el principio democrático en la Constitución, al venir a demostrar que es, únicamente, la investidura parlamentaria la que otorga efectos jurídicos constitutivos a la designación o nombramiento del Presidente del Gobierno. De tal forma, se viene a descartar, sin ambages, la tentación de concebir a la propuesta regia como la expresión de una requerida primera confianza, a la que después vendría a sumarse la de la Cámara, tal y como era característico del parlamentarismo dualista de origen decimonónico, sistema, por cierto, mantenido, aún, en ordenamientos democráticos vigentes, tanto monárquicos como republicanos ${ }^{47}$.

Además, conviene, en todo caso, relativizar la exclusividad del monopolio del ejercicio del llamado «derecho de presentación» del candidato a la Presidencia del Gobierno por parte del monarca, habida cuenta de que el Congreso puede desarrollar dicha competencia, si bien de forma extraordinaria y reactiva, tras aceptar al candidato propuesto por el rey y articular seguidamente una moción de censura constructiva, incorporando a un candidato alternativo propio (art. $113 \mathrm{CE}$ ).

45. Cfr., al respecto, el trabajo fundamental de A. M. CALERo Amor, «La prerrogativa regia en la Restauración: teoría y práctica (1875-1902)», Revista de Estudios Políticos, nº 55, 1987, pp. 273-315. También, M. Artola Gallego, «Los partidos políticos», Partidos y programas políticos: 1808-1936, Madrid, Alianza, 1991, Tomo I, pp. 321-322 y 349

46 J. TOMÁs Villarroya, «La prerrogativa presidencial durante la II República», Revista de Estudios Políticos, no 16,1980 , pp. 59-87.

47 G. De Vergottini, Diritto costituzionale comparato, Padova, Cedam, 2013, pp. 356 y ss. 
Asimismo, no debemos olvidar que la actuación regia ha de ser, en todo momento, convalidada por el Presidente del Congreso, lo que conlleva su examen y control. Así, a éste la Constitución le ha atribuido el refrendo tácito o implícito de aquélla a lo largo de la fase de consultas. Refrendo que se manifiesta expresamente, tanto cuando se sustancia en la contrafirma de la propuesta regia del candidato a Presidente del Gobierno, la cual se estampa en el documento signado por el monarca, publicado en el Boletín Oficial de las Cortes; como cuando advera el nombramiento regio del Presidente del Gobierno, una vez investido éste en el Congreso, en el Boletín Oficial del Estado. En todas estas ocasiones, el concurso del Presidente de la Cámara viene a implicar una suerte de constatación de la corrección de los actos regios, en relación a las previsiones del art. 99 CE y a los usos y convenciones que mediatizan su interpretación y aplicación.

De ahí que quepa considerar la posibilidad de su negativa a refrendar los actos y decisiones del monarca que considere abiertamente contrarios a lo dispuesto en aquéllos. Así, es claro que una eventual propuesta regia de un candidato que desoiga o no tenga en cuenta, durante la fase de consultas, el criterio mayoritario que, al respecto, le hayan trasladado los grupos políticos con representación parlamentaria, no tiene por qué merecer el respaldo, expresado a través del refrendo, del Presidente del Congreso, lo que invalidaría dicha propuesta ${ }^{48}$. Como tampoco ninguna otra actuación protagonizada por el rey y considerada por aquél exorbitante.

Y es lógico que así sea, de acuerdo con el modelo parlamentario racionalizado, adoptado por la Constitución, por mucho que la exigua jurisprudencia constitucional existente, reducida, hoy, a las SSTC 5/1987 y 8/1987, se limite a señalar que el refrendo únicamente traslada al sujeto que lo emite la eventual responsabilidad política derivada del acto regio de proposición del candidato, con lo que viene a disociar el ejercicio de la competencia, de la atribución de la responsabilidad. Y es que no cabe deducir de tan mínimo postulado que la conducta a desempeñar por el Presidente del Congreso haya de ser meramente pasiva y deferente con el proceder del rey, limitándose a asumir y dar por válidas cualesquiera decisiones que aquél adopte, sin incidir en su contenido, como si su misión sólo consistiera en actuar como mero canal de transmisión parlamentaria de las mismas $^{49}$.

Bien al contrario, no hay que olvidar que, a lo largo del procedimiento para el nombramiento del Presidente del Gobierno, el Presidente de la Cámara ha debido tener, en todo momento, puntual conocimiento, lo que implica inevitablemente su aprobación, de cuantas actuaciones haya desarrollado el rey durante la fase de consultas, hasta a la materialización de su propuesta. Ello

48 J. Vintró i CASTELls, «El procedimiento para el nombramiento del Presidente del Gobierno», op. cit., p. 1659.

49 L. López Guerra, «Las funciones del rey y la institución del refrendo», VVAA, Estudios de Derecho Público. Homenaje a Juan José Ruiz-Rico, op. cit., pp. 151-161. 
revela el deber que al mismo se encomienda de ejercitar, de modo constante, una forma sutil de control material, y no sólo certificador o formal, de los actos del Jefe del Estado orientados a la presentación de un candidato a la Presidencia del Gobierno. En todo caso, la permanente adecuación del proceder del monarca a la Constitución y a los usos y convenciones existentes ha evitado la generación, hasta el presente, de ningún tipo de crisis a ese respecto.

Aun así, un cometido como el indicado, difiere cualitativamente de la competencia que el proyecto o «borrador» presentado por la Ponencia Constitucional asignaba al Presidente del Congreso, en su art. 85, que no era otra que la de elegir, por sí mismo, a dicho candidato a presidir el Gobierno, de entre los propuestos por los grupos parlamentarios; atribución ésta que le fue definitivamente arrebatada en el Anteproyecto constitucional, desplazándola al rey en su art. $97^{50}$. Ciertamente, de haberse mantenido aquélla, conforme a su redacción original, se habría emulado la práctica seguida en Suecia o en Japón, monarquías éstas donde, culminando una evolución tendente a desapoderar al monarca de cualquier competencia en relación al ejercicio de la forma parlamentaria de gobierno, se sustrae la iniciativa de presentación del candidato, antaño atribuida a aquél, dando traslado de la misma al Presidente del Riksdag o de la Dieta Nacional, respectivamente; ejemplo éste que ha sido seguido, en España, en el ámbito institucional de las Comunidades Autónomas ${ }^{51}$.

Y es que nada impide cuestionar la razón de ser de una atribución tal en favor del monarca, por muy reglada por los usos constitucionales que se encuentre la misma. No en vano, la justificación invocada durante la discusión del precepto constitucional en favor de aquélla no se sostiene ya. Así, motivaciones fundadas en la conveniencia de atribuir al rey, en los inciertos comienzos de la nueva etapa política que entonces se iniciaba, una, aún considerada imprescindible, «función arbitral», carecen hoy de justificación alguna ${ }^{52}$. Esto explica por qué, siguiendo un distinto criterio, alimentado, por experiencias especialmente desafortunadas, dicha competencia haya sido suprimida en las Monarquías de Suecia y Japón, estados que han preferido apartar material y, a veces, incluso, formalmente, al Jefe del Estado del proceso de nombramiento del Primer Ministro o Presidente

50 Vid., las Actas de la Ponencia constitucional, publicadas en la Revista de las Cortes Generales, $\mathrm{n}^{\circ} 2$, 1984, pp. 251-419. Comenta el texto y las enmiendas I. Torres Muro, «El refrendo de la propuesta real de candidato a la Presidencia del Gobierno», Revista de Estudios Políticos, n ${ }^{\circ}$ 8, 1995, pp. 145-163; en especial, p. 148 y ss.

51 Con la particularidad de que, en Suecia, el rey es tan ajeno al proceso que ni siquiera nombra formalmente al Primer Ministro investido por el Riksdag. Ese cometido le corresponde, asimismo, al Presidente de la Cámara. Vid., al respecto, T. LARssen, «The Crown of the State», Res Publica, Vol. XXXIII, 1991/1, pp. 49-60.

52 M. Herrero Y Rodríguez de Miñón, señala como modelo referencial de la regulación española el art. 45 de la Constitución francesa de 1946. Así, cfr., su trabajo «Les sources étrangeres de la Constitution», Pouvoirs, no 8 , 1979, pp. 97-107. 
del Gobierno ${ }^{53}$. Y así ha sucedido sin que ello haya redundado, sino más bien al contrario, en detrimento de la significación simbólico-representativa que posee la Corona en aquéllos, en tanto que magistratura moral, dotada de «auctoritas», que no de «potestas».

Mas cada país tiene su historia, y no existe un prototipo puro o ideal de Monarquía parlamentaria, sino tantos como estados han asumido la variante monárquica de la forma parlamentaria de gobierno. Y dado que la Corona, en España, ha ejercido su competencia en la materia de referencia con plena corrección constitucional, demostrando así su funcionalidad, no hay por qué cuestionarse el concurso neutral de la figura del rey en un procedimiento que requiere, en los últimos tiempos más que nunca, de fieles y rigurosos aplicadores del mismo, más que de interesados árbitros, afanados por hacer de aquél un uso favorable a la facción política a la que representan.

\section{CONCLUSIONES.}

Creo así poder afirmar, en atención a lo hasta ahora expuesto, que el sistema o modelo diseñado por la Constitución, en aras de efectuar el nombramiento del Presidente del Gobierno, conserva toda su vigencia, al haber superado las difíciles pruebas de resistencia a las que, hasta el presente, ha sido sometido. Aun así, en vistas de la experiencia acumulada, quizá sea oportuno proponer la introducción de algunas correcciones que impidan el bloqueo de la elección del Presidente del Gobierno. Mas ninguna de ellas afecta al Jefe del Estado, cuya actuación, apegada escrupulosamente a la Constitución y orientada, en todo momento, a la promoción del interés general, se ha demostrado invaluable. Así se constató, particularmente, cuando durante la efímera $\mathrm{XI}^{\mathrm{a}}$ Legislatura, impidió el bloqueo o la paralización del procedimiento, dando curso al mismo, al tiempo que hacía caso omiso a las falsas salidas que le eran sugeridas.

A este respecto, no debemos olvidar que se trata de un procedimiento esencialmente diseñado para situar en su centro a los grupos políticos con representación parlamentaria, que son sus protagonistas naturales, y no a ninguna institución, pretendidamente arbitral, sustitutiva o auxiliar de los mismos. Corresponde, por tanto, a aquéllos, como es propio que suceda en toda democracia parlamentaria, alcanzar el acuerdo y otorgar su confianza al candidato que mejor consideren. Y nadie podrá sustituir su criterio, ni privarlos de su responsabilidad. Así, podrán discutirse eventuales proyectos de reforma constitucional destinados a allanar la investidura del candidato postulado, modificando el sistema de votación establecido, a los efectos de acoger la práctica seguida en

53 O. Kimminich, «Das Staatsoberhaupt in der parlamentarischen Demokratie», Veröffentlichungen der Vereinigung der Deutschen Staatsrechtslehrer, 25, 1967, pp. 2-94. 
algunas Comunidades Autónomas, sin reparar, quizá, en que tales sistemas, si bien facilitan, considerablemente la elección del Presidente, lo hacen a costa de no garantizar la estabilidad del Gobierno por aquél formado ${ }^{54}$.

Por mi parte, soy partidario de respetar la regulación constitucional vigente, al considerarla técnicamente acertada. Considero así que la misma en modo alguno complica la investidura presidencial, siendo consecuente con la intención que anima al modelo parlamentario adoptado, la cual no es otra que proporcionarle solidez al Ejecutivo que de ella surja. Además, su carácter abierto y sumario facilita la aparición de usos y prácticas que la complementan y actualizan. A lo sumo, creo conveniente introducir una limitación temporal razonable que restrinja la libertad que el Reglamento del Congreso de los Diputados concede al Presidente del Congreso para convocar el pleno de investidura, ya que la regulación actual, si se compara con la de las Comunidades Autónomas, desajusta y no se compadece con los tiempos marcados por la Constitución a lo largo del procedimiento, prolonga potencial e indefinidamente la situación de interinidad del candidato propuesto por el rey y evita introducir un elemento de presión a los grupos políticos propiciatorio del acuerdo.

Por lo demás, de confirmarse, según parece, el nuevo escenario político, sólo cabe confiar en que el nuevo y más fragmentado sistema de partidos, resultante de los procesos electorales recientes, acabe asumiendo, sin aspirar a forzarlas, las previsiones constitucionales vigentes, desde el convencimiento de que las mismas no deben ser consideradas freno sino cauce de expresión de sus legítimas aspiraciones.

\section{$* * *$}

TITLE: The Crown and the proposal of candidate to President of the Government: new practices according to old norms.

ABSTRACT: The constitutional model of election of the President of the Government in Spain retains all its validity, having overcome the difficult tests of resistance to which it has hitherto been subjected. Even so, in view of the accumulated experience, it may be appropriate to propose the introduction of some corrections that prevent the constitutional provisions from being forced, in accordance with spurious interests. But none of them affects the role played by the Crown in this procedure since its performance, scrupulously adhering to the Constitution and oriented at all times to the promotion of general interest, has proved invaluable. In this respect we must not forget that this is a procedure essentially designed to place political groups with parliamentary representation, which are its natural protagonists, and not to any institution, allegedly as an arbitrator, substitute or an auxiliary. It is therefore up to them, as it is proper to happen in any parliamentary democracy,

54 En el País Vasco (art. 5 de la Ley 7/1981, de 30 de junio, sobre el Gobierno) y en Asturias (art. 3 de la Ley 6/1984, de 5 de julio del Presidente y del Consejo de Gobierno del Principado de Asturias), no cabe bloquear la elección del Presidente. Así, los diputados no pueden votar en contra si, en la primera votación, ningún candidato alcanzó la mayoría absoluta. Sólo podrán votar a favor o abstenerse. De ese modo, será investido el candidato que obtenga un mayor número de votos favorables. 
to reach agreement and give their confidence to the candidate they consider best. And no one can substitute their criteria, nor deprive them of their responsibility.

Resumen: El modelo de elección del Presidente del Gobierno diseñado por la Constitución, conserva toda su vigencia, al haber superado las difíciles pruebas de resistencia a las que, hasta el presente, ha sido sometido. Aun así, en vistas de la experiencia acumulada, quizá sea oportuno proponer la introducción de algunas correcciones que impidan que se fuercen las previsiones constitucionales, de acuerdo con intereses espurios. Mas ninguna de ellas afecta a al cometido que desempeña la Corona en dicho procedimiento, dado que su actuación, apegada escrupulosamente a la Constitución y orientada, en todo momento, a la promoción del interés general, se ha demostrado invaluable. A este respecto, no debemos olvidar que se trata de un procedimiento esencialmente diseñado para situar en su centro a los grupos políticos con representación parlamentaria, que son sus protagonistas naturales, y no a ninguna institución, pretendidamente arbitral, sustitutiva o auxiliar de los mismos. Corresponde, por tanto, a aquéllos, como es propio que suceda en toda democracia parlamentaria, alcanzar el acuerdo y otorgar su confianza al candidato que mejor consideren. Y nadie podrá sustituir su criterio, ni privarlos de su responsabilidad.

KEY WORDS: Crown, parliamentary Monarchy, proposal, President of the Government, party system.

Palabras Clave: Corona, Monarquía parlamentaria, propuesta, Presidente del Gobierno, sistema de partidos.

FECHA DE RECEPCIÓN: 26.05.2017

FECHA DE ACEPTACIÓN: 26.07.2017 